\title{
PHYSICAL DEVELOPMENT ANALYSIS ACCORDING TO ANTHROPOMETRIC INDICATORS OF MALE STUDENTS IN THE TRAKIA UNIVERSITY
}

\author{
P. Angelova* \\ Medical College, Trakia University, Stara Zagora Bulgaria
}

\begin{abstract}
It is currently considered that health assessment systems should include a complex of morphological, functional, psychological indicators of the state of the organism. The aim of the research is analyzing the development of the physical structure of male university students considering the anthropometric indicators height, weight and chest.

Materials and methods - the research is conducted of 2017/2018 at Trakia University in Bulgaria. We used the anthropometric method. Those indicators are used for calculating the Pine's Index, Erisman's Index, The Index of Brugsh and Indicator for body development. Results: The biggest part from the students with the most strongly developed bodies $(85.96 \%)$, calculated by the index of Pine. The evaluation of the chest development is calculated by means of the thoracic-growth index of Burgsh relative part of students with wide chest is the biggest - 50\%. According to the Index of Erisman, whouses the indicators of height and chest to determine their development, the relative portion of students with good development of the latter is $85.93 \%$. Conclusion: predominant are the students of normotonic and athletic type, with good development of chest, even reaching significant levels of broad-chest size and strong body development.
\end{abstract}

Key words: Erisman's Index, anthropometry, students, The Index of Brugsh, Pine's Index

\section{INTRODUCTION}

The evaluation of the physical development of the young students is of significant interest, since it is a leading indicator, defining the health condition during the research period and the future perspectives. We do not find enough information about research on physical development at the age of 19 to 25 years. We drew attention to some gaps in the research field by collecting anthropometric data in a random sample of college students. This can serve to clarify the real physical development of young people. Investigations of university students' physical development are main priority of the specialist in the academic and sports education. Important is the question related to clarifying the level of physical health of students (Bykov, 2003). The 'height',

\footnotetext{
*Correspondence to: Petya Angelova, Trakia University Medical College, Bulgaria, Stara Zagora 6003, Georgi Apostolov str. 14, E_mail: pe_angelova@abv.bg phone number: +359886441285
}

'weight' and 'chest' indicators are key characteristics defining the physical development, according to authors such as Bashkirov (1962). Others, like Vorobyova (1998); Slantchev et al. (1992); Sukhanov (1996), Utkualp (2015) claim that the socioeconomic and the hygienic living conditions determine the physical condition. Pribis (2010); Gropper (2012); Hootman (2017) examine changes in anthropometry and body composition in students, but there is no data on chest development, breathing capacity, and body type identification. In researches of Kuznetsova (2005) it is stated that $35 \%$ of boys have narrow chests. What is more, the analysis conducted amongst youngsters aged 17-21 years reveals that students do not fulfill the Russian physiological standard and $1 / 3$ of the young men have disharmonic physical development, due to disproportionality between height, weight and age.The improved physical condition, determined by the acceleration and the already mentioned factors, 
could contribute to the better development of physical capability and involving the university youth in more sport activities. This would decrease the disproportion between good physical condition and the reduced physical capacity (Slantchev et al. 1992).The aim of the research is analyzing the development of the physical structure of male university students considering the anthropometric indicators height, weight and chest.

\section{MATERIALS AND METHODS}

Anthropometry includes a set of simple, inexpensive and non-invasive methods to assess both the size and composition of the human body - Ercan (2012); Wang (2000); Popov (1959).The research is conducted of 2017/2018 at Trakia University in Bulgaria. The researchers held a meeting with possible volunteers $n=67$ at the institution. They were explained the goals and ethical procedures and gave their informed consent. Trained evaluators performed data collection at two different moments. For recording the data for the 'height', 'weight' and 'chest' indicators of the examined students we used the anthropometric method. Anthropometric measurements were taken in all the study participants by the same person in the morning with the subjects wearing light sports clothes without shoes. The following anthropometric variables were collected: a) height $(\mathrm{cm})$ using a stadiometer with a $0.1 \mathrm{~cm}$ accuracy; weight using a digital scale with a $0.01 \mathrm{Kg}$ accuracy. Those indicators are used for calculating the Pine's Index, Erisman's Index, The Index of Brugsh and Indicator for body development. The mathematical-statistical processing of the data is done through the program product IBM SPSS Statistics Subscription and includes variational, comparative and graphic analyses.

\section{RESULTS}

At the current examination of Trakia University students the both of the average values of chest at rest is $99.45 \mathrm{~cm}$ and 103.59 $\mathrm{cm}$ while inhaled, (Table 1). The averages values while exhaling are $99.22 \mathrm{sm}$.

Table 1. Anthropometric indicators

\begin{tabular}{|l|l|l|l|l|l|l|}
\hline N & Mean & Minimm & Maximum & Range & S td. Deviation \\
\hline Height - standing & 64 & 174.98 & 160 & 192 & 32 & 7.581 \\
\hline Body mass & 64 & 78.11 & 50 & 128.30 & 78.3 & 15.34 \\
\hline Chest at rest & 64 & 99.45 & 81 & 129 & 48 & 9.142 \\
\hline Chest - inhaled & 64 & 103.59 & 85 & 131 & 46 & 8.587 \\
\hline Chest - exhaled & 64 & 99.22 & 80 & 129 & 49 & 9.293 \\
\hline Chest - average & 64 & 100.76 & 82 & 129.67 & 47.67 & 8.97 \\
\hline Index of Pine & 64 & -3.88 & -82.97 & 35.03 & 118 & 21.16 \\
\hline Index of Erisman & 64 & 13.26 & -3.33 & 42.16 & 45.49 & 8.05 \\
\hline Index of Burgsh & 64 & 57.58 & 48.18 & 74.09 & 25.90 & 4.60 \\
\hline $\begin{array}{l}\text { Indicator of body } \\
\text { development }\end{array}$ & 64 & -3.87 & -82.96 & 35.03 & 118 & 21.16 \\
\hline
\end{tabular}

Figure 1 illustrates the relative shares of distribution of students with different level of physical development, calculated by the index of Pine. The biggest part form the students with the most strongly developed bodies $(85.96 \%)$. The ones with weak, average or fairly good development form equal portions (4.68\%). A drawback of this index is that it calculates good values for overweight people with short height and incorrect development, or in other words - it considers them wrongly as well developed bodies.

According to the Index of Erisman, whouses the indicators of height and chest to determine their development, the relative portion of students with good development of the latter is $85.93 \%$ (Figure 2). The ones with mediumdeveloped chest form $10.94 \%$, and those with weakly development - only $3.13 \%$. 
Figure 1 - Relative shares of level of physical development according to the index of Pine

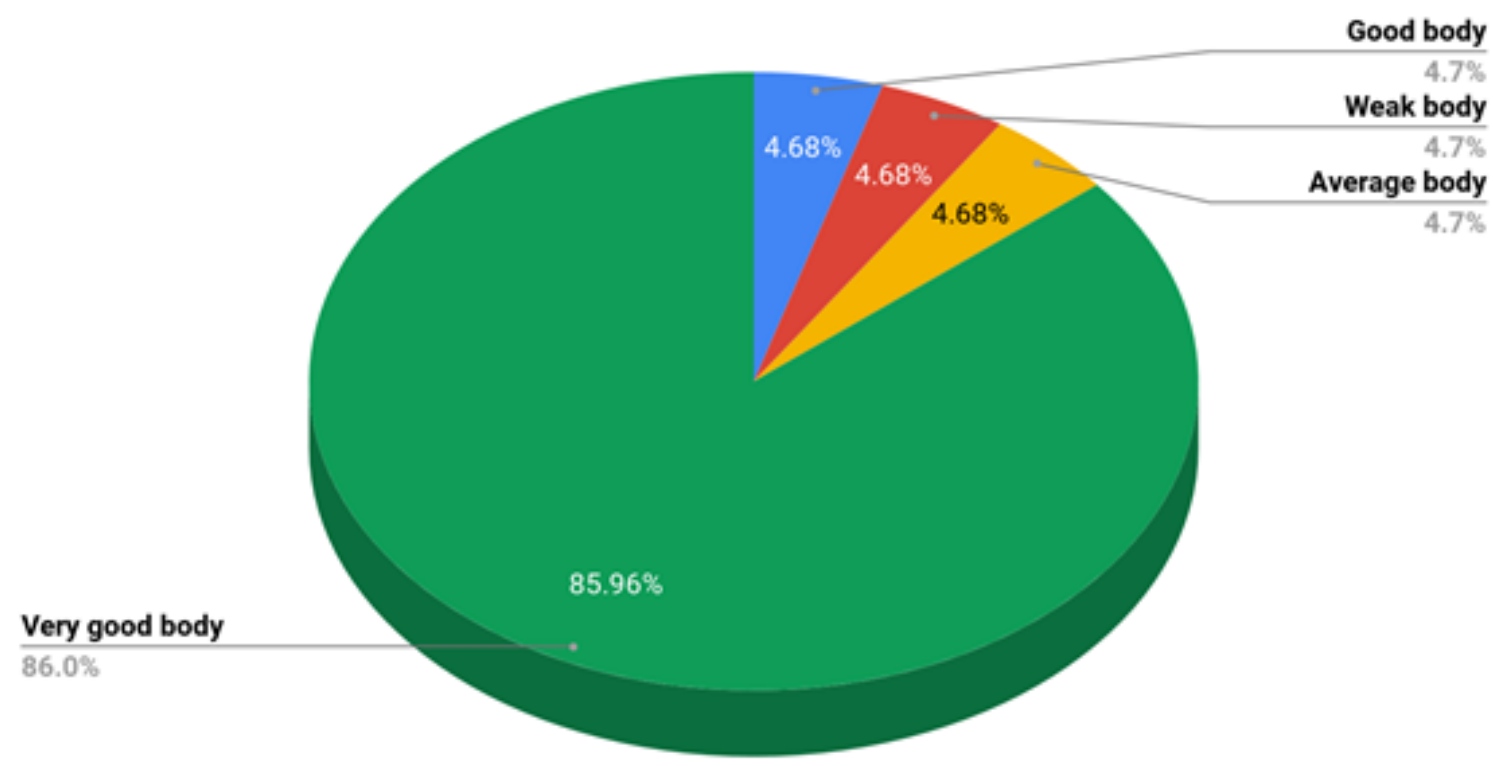

Figure 2 - Level of chest development calculated through index of Erisman

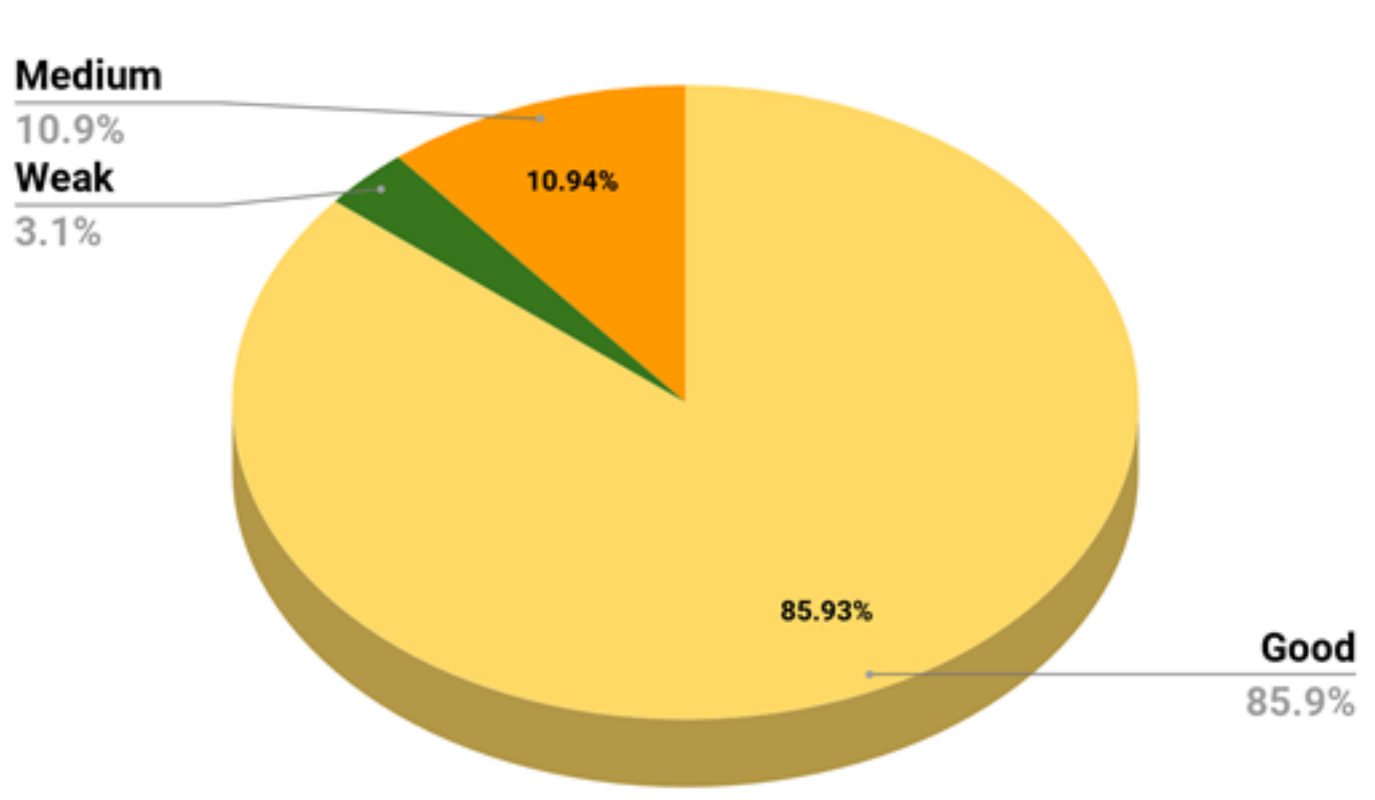

$\underline{\text { d body }}$

$4.7 \%$

$4.7 \%$

je body

$4.7 \%$
The evaluation of the chest development, calculated by means of the thoracic-growth index of Burgsh is illustrated on Figure 3. There it can clearly be seen that the relative part of students with wide chest is the biggest $50 \%$. The ones with medium-developed chest also form a not insignificant share - 39.06\%, and those with narrow chest $-10.94 \%$.

There is another index of body development, which uses not only height, but also average chest size and body mass. The indicators calculated by means of this index are depicted below on Figure 4. Evidently, According to the Index of Erisman, whouses the indicators of height and chest to determine their development, the relative portion of students with good development of the latter is $85.93 \%$ The share of people with normal body development is $15.63 \%$, with average $-6.25 \%$ and with weak development $-4.69 \%$. 


\section{Figure 3 Chest development according to the index of Burgsh}

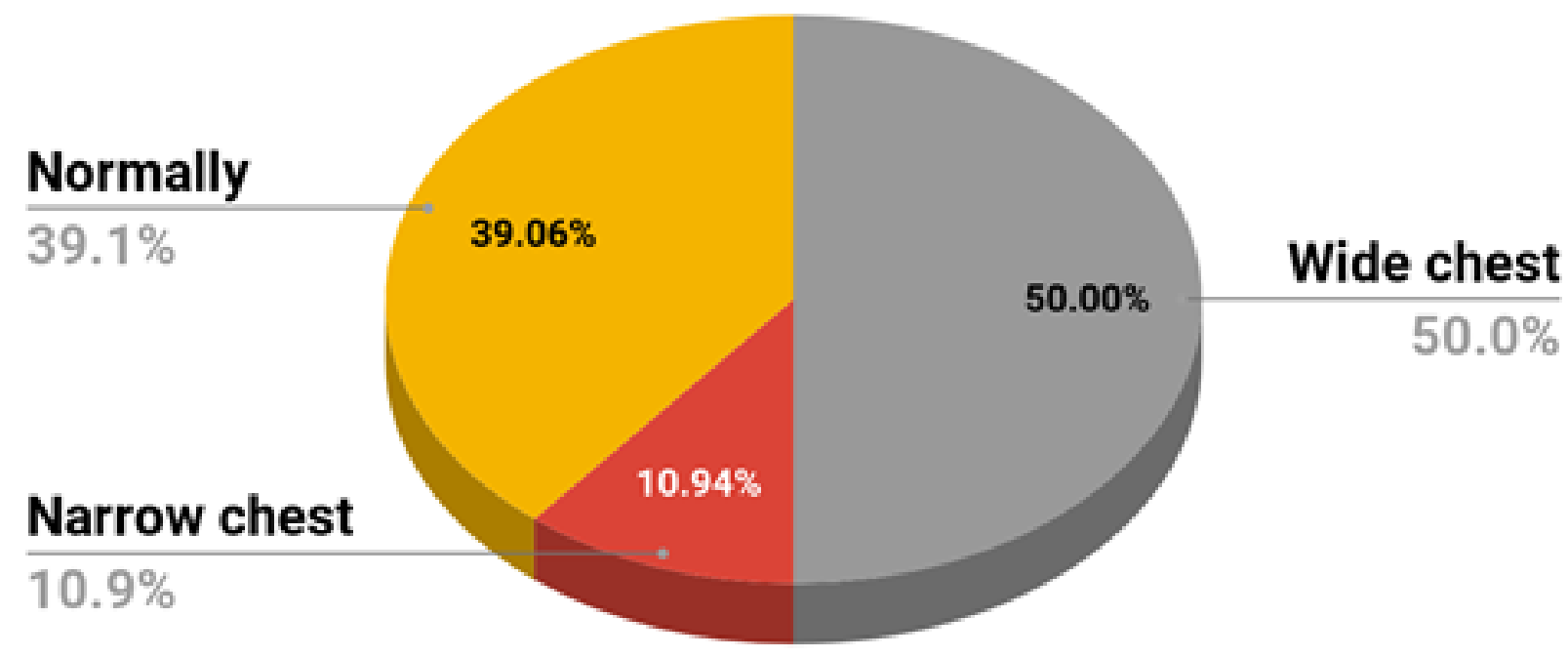

Figure 4 - Relative shares calculated by index of body development

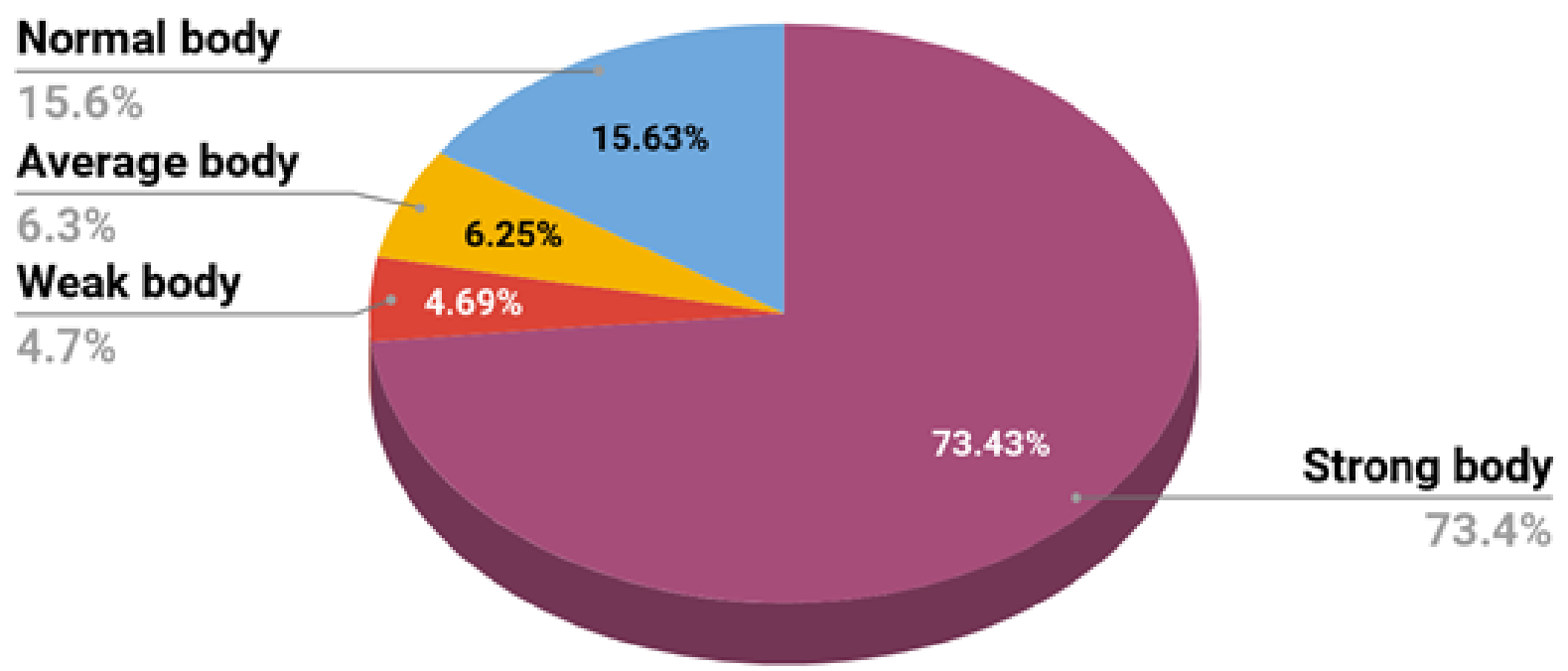

\section{DISCUSSION}

The lack of assessment in the majority of works of the level of somatic health of students makes it difficult to objectively assess the situation and effectively manage the process of strengthening health with the help of physical exercises during the period of study at the university. Somatic health studies of students do Kuzhuget (2012); Pyatunina (2018). Pribis (2010) found that there is a small and declining minority of male and female students who have a physical form and suggests using strategies to counteract the current trend and to help young people improve physical fitness.
Sterkowicz-Przybycień (2011) she published data on anthropometric measurements comparing the populations of athletes and nontraining students from Poland to assess the proportionality of the body and indicates significant differences that are also seen in the width of the chest, thighs, elbow, and foot. Lobygina et al. (2017) proposes to assess the indicative level of health, especially when studying a large number of people, simple and at the same time informative, maximally evaluating different parameters methods. National research in Bulgaria in Bulgaria of Slanchev et al.(1992) for men aged 19-24 
indicate the average values of chest at rest is 89.6 - $92.6 \mathrm{~cm}$ and $95.6-122.0 \mathrm{~cm}$ while inhaled. At the current examination of Trakia University students the both of the average values of this indicator are impressive and which is typical for older men (see table 1). According to National research in Bulgaria the averages while exhaling are 86.7- 89.3, while among the examined Trakia University students are bigger than one. Our study also concludes that predominant are the students of normotonic and athletic type, with good development of chest, even reaching significant levels of broad-chest size and strong body development. The groups of students of asthenic type with narrower, weakly developed and flat chest form the smaller share.The chest size indicates a relative increase in comparison to the same indicators of National research (1992), made amongst men of the same age.

\section{REFERENCES}

1. Bashkirov, P. N., Study of the physical development of the human, Moscow, Moscow State University, 1962, p. 250254.

2. Bykov, E. V., Uskov, G. V., Chipyshev, A. V., Belov, V. V., Programs of training regimes for students with different levels of functional state, Theory and practice of physical culture. 2003, -№6. -p. 17-19.

3. Ercan, I., Ocakoglu, G., Sigirli, D., Ozkaya, G., Statistical shape analysis and usage in medical sciences. Turkiye Klinikleri Journal of Biostatistics. 2012;(4):27-35.

4. Gropper, S. S., Simmons, K. P., Connell, L. J., Ulrich, P. V., Changes in body weight, composition, and shape: a 4-year study of college students. Appl Physiol Nutr Metab. 2012:1118-1123. [PubMed].

5. Hootman, K. C., Guertin, K. A., Cassano, P. A., Longitudinal changes in anthropometry and body composition in university freshmen. Journal of American college health: J of ACH. 2017;65(4):268276. doi:10.1080/07448481.2017.1280498.

6. Kuznetsova, M. V., Peculiarities of the physical development of the student youth of Orenburg region, the author's abstract, dissertation, Orenburg, 2005. - 25 p.

7. Lobygina, N. M., Tikanov, A. O., Krylovsky, A. Yu., Kravchenko, O. E., Analysis of somatic health of students of the special medical group of Altai State Medical University by Gl. L. Apanasenko,
Scientific and Periodical Journal "Human Health, Theory and Methodology of Physical Culture and Sport", 2017. - No. 1 (4).-- P. 65-72.

8. Popov, M., Anthropology of the Bulgarian Nation. Fiziçeski Oblik na Bılgarite. Sofya, Bulgaria: BAN; 1959.

9. Pribis, P., Burtnack, C. A., McKenzie, S. O., Thayer, J., Trends in Body Fat, Body Mass Index and Physical Fitness Among Male and Female College Students. Nutrients. 2010;2(10):1075-1085. doi:10.3390/nu2101075.

10. Slanchev, P., Yanev, B., Genov, F., Shcterev, P., Boev, D., Sepetliev, B., Zakhariev, Physical development, physical capacity and neuro-psychic reactivity to the population of Bulgaria, BSFKS, S., 1992. p. 30-31.

11. Sterkowicz-Przybycień, K. L., Sterkowicz, S., Żarów, R. T., Somatotype, Body Composition and Proportionality in Polish Top GrecoRoman Wrestlers. Journal of Human Kinetics. 2011;28:141-154. doi:10.2478/v10078-011-0031-z. [PubMed].

12. Sukhanov, N. N., Physical development of children and adolescents by the end of the twentieth century; connection with biological and socio-hygienic factors, Thesis Moscow, 1996 - p. 301.

13. Utkualp, N., Ercan, I., Anthropometric Measurements Usage in Medical Sciences. BioMed Research International. 2015;2015:404261. doi:10.1155/2015/404261. [PubMed].

14. Vorobyeva, E. A., Physical, sexual, mental development, functional activity of the body of adolescents aged 15, Dissertation, Ivanovo, 1998. - p. 174.

15. Wang, J., Thornton, J. C., Kolesnik, S., Pierson, R. N., Jr., Anthropometry in body composition. An overview. Ann NY Acad Sci., 2000 May;904:317-26 [PubMed].

16. Kuzhuget, A. A., Features of physical development, cardiorespiratory function and somatic health of students, depending on the organized motor activity, 2012 http://www.dissercat.com/content/osobennosti -fizicheskogo-razvitiya-funktsii-

kardiorespiratornoi-sistemy-isomaticheskogo-zdo

17. Pyatunina, O. I., Peculiar features of physical preparation of students studying at the Shukshin Altai State Humanities Pedagogical University. Health, Physical Culture and Sports, 1 (8), pp. 16-26 (in Russian). 2018 URL: http://journal.asu.ru/index.php/zosh 